СБОЕВ Александр Николаевич,

канд. филол. наук, доцент кафедры китаеведения ДВФУ (г. Владивосток).

Электронная почта: sboev.an@dvfu.ru

НОВГОРОДОВА Антонина Владимировна

магистр ДВФУ (Востоковедение и африканистика) (г. Владивосток).

Электронная почта: tonya.novgorodova@bk.ru

\title{
Речевое воздействие в интернет-рекламе на китайском языке
}

\section{УДК 811.581}

речевое воздействие, речевая стратегия, речевая тактика, интернет-реклама, блогер Viуа
Для иитирования:

Сбоев А. Н., Новгородова А. В. Речевое воздействие в интернет-рекламе на китайском языке // Известия Восточного института. 2021. № 3. C. $108-121$. DOI https://doi.org/10.24866/2542$1611 / 2021-3 / 108-121$
DOI https://doi.org/10.24866/2542-1611/2021-3/108-121

\begin{abstract}
Результаты исследований речевого воздействия в разных языках могут применяться для налаживания межкультурной коммуникации в самых разных сферах. Объект данного исследования - речевое воздействие, предметом выступают особенности речевого воздействия в китаеязычном рекламном дискурсе. И более конкретно - в рекламном интернет-дискурсе. Материал исследования - прямые эфиры интернет-блогера Viya. В ходе исследования определены стандартная стратегия и последовательность в представлении товара популярного интернет-блогера Viya, а также применяемые коммуникативные тактики.
\end{abstract}

\section{Введение}

Реклама в соответствии с основными задачами может быть определена как целенаправленная манипулятивная человеческая деятельность. Так как целью рекламы является привлечение покупателей и клиентов, то важно не столько информировать о товаре или услуге, сколько убедить потенциального покупателя приобрести товар или воспользоваться услугой, воздействуя на его мышление, поведение, предпочтения.

Одной из важных форм маркетинга в социальных сетях является маркетинг влияния. В последние годы эта форма маркетинга стала очень популярна и часто используется рекламодателями.

Маркетинг влияния - это способ продвижения товара или услуги с помощью лидеров мнений и знаменитостей, их называют «инфлюенсерами». Инфлюенсерами могут быть все, у кого большая аудитория в социальных сетях и к чьему мнению прислушивается аудитория, это блогеры, журналисты, участники телешоу, политики, видеографы, фотографы и т. д. Но в отличие от рекламы у знаменитостей, реклама у лидеров мнений считается более доступной и правдоподобной [19]. Инфлюенсеры достигают главной цели - продажи товара - в том числе и за счёт определённых форм речевого воздействия.

В основу нашего исследования легли прямые эфиры (стримы) популярного блогера с ником Viya (薇娅), стримы на платформах Таобао, Weibo, Bilibili c её участием набирают десятки миллионов просмотров в интернете, а рекламируемый товар раскупается за минуты.

Viуa - известный блогер, певица, ведущая прямых эфиров на платформе Таобаo, Weibo, Bilibili, член Всекитайской федерации молодёжи. История её успеха начинается с 2003 года, 
когда она со своим молодым человеком открыла в Пекине магазин женской одежды площадью 6 м2. Позднее магазин стал приносить большую прибыль, и они открыли ещё 6 магазинов в других городах. В 2012 году из-за популяризации электронной торговли они закрыли все семь офлайн-магазинов и открыли онлайн-магазин на Таобао. В 2015 году на ежегодной распродаже 11 ноября интернет-магазин, которым управляли Viya и её муж, заработал более 10 миллионов за день. После этого многие компании стали сотрудничать с Viya, а в 2016 году её пригласили в качестве ведущей.

Сегодня её аудитория на Таобао составляет около 40 млн. подписчиков, а в Weibo более 18 млн. Весной 2020 г. во время прямого эфира на Taobao Viya продала право на запуск ракеты-носителя KZ-1A, a осенью того же года презентовала товары из РФ, которые были раскуплены за 30 минут, при этом российский стрим посмотрели свыше 38 миллионов человек. В том же году она заняла 38-е место в списке китайского Forbes и была признана «Самой влиятельной женщиной в предпринимательской деятельности» по мнению журнала Fortune. За её умение успешно продавать и заключать крупные сделки её наименовали «королевой продаж».

Одна из причин её успеха в онлайн-торговле заключается в том, что Viуа сама пробует продукт, тестирует его и пользуется им. Приоритетом для неё является качество товара и продукта, которые она предлагает своей аудитории. Многие люди заказывают товары, рекомендованные Viya, потому что доверяют её выбору. Она рекламирует товары как больших, так и малоизвестных брендов, если считает, что товар соответствует по цене и качеству.

Большой объём продаж товаров, рекламируемых Viуa, который достигается за счёт определённых коммуникативных стратегий, тактик и ходов, определяет актуальность данного исследования.

Материалом для данного исследования послужили семь рекламных видеороликов и прямых трансляций Viya, размещённые на платформе YouTube и Bilibili, общей продолжительностью 5 часов 47 минут.

Цель исследования - выявить частотные коммуникативные стратегии, тактики и ходы, используемые в прямых эфирах блогером Viya, побуждающие китайских потребителей покупать рекламируемые товары.

\section{К понятию «речевое воздействие»}

В современной лингвистике существуют разные определения понятия «речевое воздействие». Рассмотрим несколько из них.

В работе Мальцевой В. А. понятие речевого воздействия соотносится с понятием речевого общения, взятого в аспекте его целенаправленности, и определяется как целенаправленное вербальное общение с целью изменения сознания и/или управления поведением объекта со стороны субъекта $[12,9]$.

По мнению Горло Е.А., в широком смысле речевое воздействие это любое речевое общение, которое понимается как «сложный многоплановый процесс установления контакта между отправителем и получателем, осуществляемый с помощью средств языка. А речевое воздействие, как любой акт общения относительно его направленности на то или иное изменение субъективных характеристик получателя» $[5,34]$.

Шелестюк Е.В. рассматривает речевое воздействие как «произвольное и непроизвольное воздействие субъекта на реципиента в 
процессе речевого общения в устной и письменной формах, которое осуществляется с помощью лингвистических, паралингвистических, и символических средств и определяется сознательными и бессознательными интенциями субъекта, целями коммуникации, пресуппозициями и конкретной знаковой ситуацией» $[16,25]$.

Иссерс О.С. в своей работе «Коммуникативные стратегии и тактики русской речи» связывает понятие речевого воздействия с целевой установкой говорящего. «Субъект речевого воздействия регулирует деятельность своего собеседника, его поведение, при помощи речи побуждает собеседника начать, изменить, закончить какую-либо деятельность» $[8,21]$.

Проанализировав вышеизложенные определения, а также учитывая предмет нашего исследования, в нашей работе под речевым воздействием мы предполагаем коммуникативный акт, в процессе которого субъект оказывает на объект прямое или косвенное влияние на сознательное и бессознательное, регулируя его поведение, восприятие мира, отношение к тому или иному предмету.

\section{Стратегии речевого воздействия}

Для реализации речевого воздействия используются определённые коммуникативные стратегии и тактики, исходя из цели коммуникативного акта.

Иссерс О.С. под коммуникативными стратегиями представляет «планирование процесса речевой коммуникации в зависимости от конкретных условий общения и личностей коммуникантов, а также реализацию этого плана. Иными словами, речевая стратегия представляет собой комплекс речевых действий, направленных на достижение коммуникативной цели» $[9,43]$.

Как отмечает Мирошниченко Г.А., вовлечение адресата рекламы в потребление «достигается коммуникативной стратегией, которая рассматривается как совокупность взаимообусловленных и дополняющих друг друга коммуникативных приёмов, речевых тактик, лексико-грамматических конструкций, применяемых в речевом воздействии на коммуникантов для достижения поставленных целей» [13, 217].

Рассмотрим стратегии, выделяемые японским исследователем в работе «Стратегии сообщений, информативность и привлекательность в китайской телевизионной рекламе: эмпирическое исследование». Автор выделяет три основные стратегии рекламных сообщений: когнитивные, аффективные, конативные (поведенческие). Когнитивные стратегии ориентированы на информировании о свойствах и преимуществах продукта. Аффективные стратегии связывают рекламируемый бренд с эмоциональной реакцией, позитивным образом. Цель аффективных стратегий - вызвать у потребителя положительные эмоции и перенести их на сам товар. Таким образом, потребление или использование продукта покупателем будет эмоционально насыщенным и ассоциироваться с приятными чувствами. Конативные (поведенческие) стратегии пытаются убедить потребителей придерживаться определённого поведения, это стратегии побуждения к действию и продвижения продаж [17].

Далее рассмотрим классификацию речевого воздействия в рекламе, выполненную Горячевым А.А. В своей работе «Моделирование 
речевого воздействия в рекламной коммуникации» он предложил разделить коммуникативные стратегии в рекламе на информационно-формирующие и оптимизирующие.

Информационно-формирующие стратегии - стратегии, направленные на создание обладающего воздействующим потенциалом образа объекта рекламирования $[6,70]$.

В свою очередь, информационно-формирующие стратегии в зависимости от типа создаваемой связи между ментальными репрезентациями делятся на две частные стратегии - стратегию ассоциирования и стратегию диссоциирования.

Оптимизирующие стратегии Горячев А.А. выявил по функциональным характеристикам «в зависимости от условий успешного воздействия и в том порядке, в котором происходит взаимодействие реципиента с текстом (получение сообщения - восприятие - запоминание - действие)». Оптимизирующие стратегии ориентированы на то, чтобы сделать речевое воздействие более эффективным [6, 92].

\section{Речевая тактика}

Речевая тактика рассматривается Клюевым Е.В. в качестве совокупности практических ходов в реальном процессе речевого взаимодействия, т. е. коммуникативная тактика, в отличие от коммуникативной стратегии, прежде всего соотнесена не с коммуникативной целью, а с набором коммуникативных намерений $[11,19]$.

В свою очередь, коммуникативные намерения трактуются в качестве тактического хода, являющегося практическим средством движения к соответствующей коммуникативной цели. Вся совокупность таких практических средств в реальном процессе речевого взаимодействия создаёт, как сказано, коммуникативную тактику $[11,19]$.

В работе Статкевича Е.А. «Речевые стратегии и тактики современной радиорекламы» речевые тактики определяются более обобщенно, как «речевые приемы, позволяющие достичь определённых целей в конкретной ситуации» $[14,213]$.

Следует отметить, что выбор речевой тактики зависит от многих определяющих факторов: возраста адресата, цели речевого воздействия и ожидаемого результата, половой принадлежности, социального статуса и др.

\section{Коммуникативные ходы}

Речевая (коммуникативная) тактика реализуется с помощью различных приёмов, коммуникативных ходов. Характеристика коммуникативного хода определяется исходя из его функциональной нагрузки в решении тактической и стратегической задач $[11,125]$.

Коммуникативный ход - это «вербальное или невербальное действие одного из участников, минимальный значимый элемент, развивающий взаимодействие, продвигающий общение к достижению общей коммуникативной цели» $[15,115]$.

По определению Т.А. ван Дейка, коммуникативный ход - это «функциональная единица последовательности действий, которая способствует решению локальной или глобальной задачи под контролем стратегии» $[3,274]$. 


\section{Речевое воздействие в рекламном дискурсе}

Карлсон С. отмечает, что целью рекламодателя в коммерческой рекламе является «убеждение зрителя к совершению покупки», а это можно сделать только в том случае, если между зрителем и рекламодателем установились «воображаемые» межличностные отношения. Рекламодатели могут создать их, обращаясь к зрителю напрямую, используя экзофорические ссылки «ты», «вы» или другие экзофорические ссылки, указывающие на общие знания зрителей, а также с помощью второстепенных участников, с которыми зритель может идентифицировать себя или узнать их за пределами рекламного мира - знаменитости или сложившиеся стереотипы [18].

Рассматривая коммуникативные возможности речевых тактик в рекламных текстах, Гончарова Л. М. выделяет ряд этапов воздействия на потребителя:

- привлечь внимание формой и содержанием;

- вызвать интерес к рекламируемому предложению товара/услуги;

- возбудить желание совершить приобретение;

- дать аргументы и оценки в пользу предмета рекламы;

- привести к решению совершить конкретное действие (речевое - выяснить дополнительные детали, неречевое - совершить покупку) $[4,22]$.

Авторы работы «Приемы речевого воздействия» выделяют следующие приёмы, с помощью которых создатели рекламы воздействуют на психику адресата:

Конкретность и образность ключевых слов;

Конкретность и образность качеств;

Избегание отрицательных частиц «нет» и «не»;

Речевая динамика;

Воздействие звукосочетаниями $[1,112]$.

\section{Реклама в прямом эфире в интернете}

Реклама в прямом эфире имеет свои преимущества. Так, в работе «Анализ предпочтений китайских потребителей-миллениалов в отношении каналов интернет-рекламы в Китае» авторы провели исследование среди пользователей Таобао и выяснили, что интернет-реклама в формате прямого эфира способна вызвать больший интерес потребителей к рекламируемому товару. Авторы утверждают, что зрители прямого эфира чаще ищут информацию о рекламируемом товаре и добавляют их в корзину. Более того, в прямом эфире больше информации о продуктах и скидках. Ещё одной положительной характеристикой рекламы в прямом эфире, как отмечают авторы, является то, что она фильтрует товары. Лидеры мнений выбирают часть качественных товаров, тем самым сужают выбор для зрителей. Потребители обращают внимание только на рекомендованный товар, чтобы окончательно определиться с покупкой конкретного вида товара, и прямой эфир как раз отвечает этому требованию [20].

Таким образом, в Китае за последние годы реклама в прямом эфире получила широкое распространение. Крупные и малые компании обращаются к известным блогерам, чтобы заявить о себе, привлечь новых покупателей, закрепить свои позиции на рынке.

Прямые эфиры (стримы) Viуа достаточно длительные, довольно часто она проводит их совместно с какой-либо звездой. С самого на- 
чала, когда Viуа делала прямые эфиры на площадке Таобао, она выпускала их так часто, что пользователи интернета непроизвольно запомнили её.

Китайский лингвист Чжан Юэчан отмечает, что способ представления товара у Viya - это в основном непринужденная беседа с подругами, формирующая ощущение взаимодействия при обсуждении и беседе с друзьями $[22,135]$.

Практически всегда в начале прямого эфира Viуа говорит фразу 话 不多说, 我们先来抽波奖。Не будем долго говорить, давайте сначала разыграем лотерею. Это предложение вызывает большой интерес аудитории и привлекает её внимание. Призами в лотерее являются популярные товары, например, помада марки YSL, телефоны Huawei и товары других известных брендов, например, сумки Gucci, Hermes. Viуа таким образом приковывает внимание зрителей, а в течение прямого эфира несколько раз проводит другие розыгрыши. Названия ее стримов также привлекают внимание: «Телефон в подарок! Деньги в подарок!», «Дождь из «красных конвертов»» и т.д. Из-за того, что время проведения таких лотерей неопределённое, зрителям приходится долгое время смотреть прямой эфир в ожидании. Привлечь фанатов можно только в том случае, если ценность товаров, которые разыгрываются в лотерее, будет высока. Например, 废话不多说, 先抽一台手 机送给大家。Нечего болтать попусту, давайте разыграем для начала сотовый телебон.

Розыгрыш лотереи является главной составляющей прямых эфиров блогеров-продавцов. Лотерея в начале прямого эфира может привлечь больше зрителей к просмотру прямой трансляции и активизировать атмосферу во время прямой трансляции.

\section{Стратегии и тактики речевого воздействия в рекламных видеороликах Viya}

Далее рассмотрим коммуникативные стратегии, тактики и ходы, применяемые Viуа в своих прямых эфирах.

1. Коммуникативная стратегия завоевания потребителя

Тактика предложения очевидной выгоды

Выгодность, выраженная в денежном эквиваленте, может полностью изменить решение адресата в пользу приобретения товара:

这款产品目前活动力度特别大, 第一件 39 元, 第二件只要 19 元, 第三件再减 10 元只要 9 元, 第四件免费送, 等于 67 元买了 4 件产品!

Сейчас очень много акиий на этот товар, одна по иене 39 юаней, вторая за 19, третья еще дешевле на 10, т.е. всего 9 юаней, четвёртая в подарок, так за 67 юаней можно купить четьре!

这个原价 59 元, 在我们直播间买一份只需要 49 元, 买两份, 第 二份 23 元, 还可以领 10 元优惠券。Изначально стоило 59 юаней, но во время нашего прямого эфира изена за одну 49 юаней, вторая уже по цене 23 юаня, причём можно получить ещё и купон на скидку.

Установление блогером начальной цены, а затем озвучивание цены со скидкой указывает на существенную материальную выгоду. Кроме того, для стимулирования зрителей, Viya указывает на дефицит товара.

Тактика предложения уникального товара

Языковыми маркерами данной тактики могут служить слова «уникальный», «единственный», «впервые»: 
然后有链条包、独一无二的的那个猫神链条包, 今晚也到了。不 过数量只有两线个。这个没办法这个数量只有两线个。

Также есть сумка на иепочке. Уникальная сумка с кошкой. Также в наличии сегодня вечером. Но в наличии только две сумки. Здесь ничего не поделаешь, есть только две сумки.

Тактика аргументаиия в пользу приобретения товара

Аргументация в пользу приобретения товара достигается за счет коммуникативных ходов «настойчивое убеждение», «повеление», «искусственное создание нехватки времени/количества» и «повтор».

Коммуникативный ход «настойчивое убеждение»

如果卸妆的话, 第一个选择它。 Если вbl xотите средство для снятия макияжа, в первую очередь, берите её.

我跟你们说, 这一定要买, 我们好不容易争取来的利润, 错过就 没有了，真的没有了。Я так скажу, это непременно нужно брать, нам нелегко получить выгоду, поэтому если в этот раз упустить эту возможность, потом уже не будет, точно не будет.

Коммуникативный ход «повеление»

如果有黑头一定要用它。 Если у вас угри, обязательно нужно пользоваться им.

Коммуникативный ход «искусственное создание нехватки времени/количества»

赶紧购买。倒计时开始。Скорее покупайте, начинаем обратный отсчёm.

不过这个非常少，数量非常少，非常少！59一款。我们今天直播 间39块钱一块香皇。Но количество ограничено, количество ограничено, очень мало. 59 юаней одно мыло. Сегодня у нас в прямом эфире 39 юаней одно мыло.

Коммуникативный ход «повтор»

这瓶洗发水的去屑功效超强, 我们拿到的是今年新款, 有效成分 增加了两倍, 它的原价是 199。但是, 只有今天, 只有在我们的直 播间里, 它的价格是 69 , 而且还买一瓶送一瓶! 我再讲一遍, 这一 瓶超强去屑洗发水, 原价 199 一瓶, 现在不仅买一瓶送一瓶, 还送 6 件旅行套装, 只要多少钱? 69! 来54321 上链接。 Эmom шамnyнb крайне эффективен против перхоти, в марке, которая представлена у нас сегодня, количество полезных элементов увеличено втрое. Изначальная цена - 199 юаней, но только сегодня, только в нашем прямом эфире его иена - 69 юаней, к тому же с покупкой одного флакона - второй в подарок. Я повторю ещё раз, этот шампунь суперэффективен против перхоти, изначальная иена - 199 юаней за флакон, кроме того, при покупке сейчас в подарок второй, а ещё в подарок 6 дорожных наборов, сколько за это нужно? 69!

2. Коммуникативная стратегия обращения к разуму

Тактика обращения к научным данным

Коммуникативный ход «использование научных терминов, фактов, профессиональной лексики»

现在这样的空气污染。包括空气中游离的重金属。不用卸妆吗?

Сейчас атмосбера так загрязнена. Включая ионы тяжельх металлов в воздухе. Вам не нужно снимать макияж?

В данном случае Viya апеллирует к состоянию внешней среды как фактору, влияющему на здоровье кожи лица. Использование научного термина 游离的重金属 ионы тяжелых металлов иллюстрирует серьезность проблемы и придает аргументу вескость. 
Кроме того, речевое воздействие подкрепляется риторическим вопросом, подталкивающим к размышлению о необходимости ухаживать за кожей лица.

因为它里面没有加防腐漆。这个沐浴露里面没有加防腐漆、没有 加矿物油、没有重金属、没有酒精、没有动物油, 并且通过了德国 的皮肤科的一个测试。

Потому что в его составе нет антикоррозионной краски. В составе этого геля для душа нет антикоррозионной краски, нет минерального масла, нет тяжелых металлов, нет спирта, нет животного масла, более того, крем прошел немецкий дерматологический тест.

Как правило, в рекламных текстах не рекомендуется использовать отрицания, так как считается, что они сложно воспринимаются и усваиваются, к тому же могут означать именно то, что отрицают. Но практика показывает, что в рекламном пространстве активно применяются отрицательные частицы и предлоги, это привлекает внимание аудитории. Поэтому в приведённом выше примере перечисление отсутствующих в составе вредных компонентов может послужить хорошим аргументом в пользу приобретения товара. В данном примере эффект достигается также за счёт повтора, шесть раз используется отрицание 没有.

Тактика обрашения к здравому смыслу

你以为你用是抹布啊? 你以为你脸是桌子吗? 还有那些说我根 本不化妆的妹子你站住。你以为你不化妆就不用卸妆了吗? $T b l \partial y$ маешь, что пользуешься тряпкой? Ты думаешь, что твое лиио стол? Ещё те девушки, которые говорят, что вообще не красятся, остановитесь. Ты думаешь, что, если ты не красишься, тебе не нужно очищзать лищо?

В данном случае обращение к разуму достигается с помощью риторических вопросов. На практике риторические вопросы рассматриваются как стилистические фигуры, целью которых является усиление выразительности речи. В данном примере риторические вопросы выражают открытую критику и явный упрёк в сторону адресата. Они проявляются в использовании местоимений второго лица 你 $\mathrm{mbl}$, a также в ироническом сравнении применения адресатом влажной салфетки для снятия макияжа как тряпки для стола.

Тактика аргументирования в пользу приобретения товара

Наиболее распространённый способ аргументации - описание свойств и характеристик продукта. Во время рекламы товара Viуа акцентирует внимание на том, какую пользу приносит товар для потребителя, потому что перечисление и расхваливание положительных эффектов продукта логически обосновывает его покупку.

芭妮兰的卸妆膏。（质地）像冰淇淋一样。浓妆也能卸的干净。 干手干脸, 乳化也很快, 温水冲洗就干净了。Очищаютий бальзам для снятия макияжа Banila. (Текстура) как мороженое. Эффективно снимает плотный макияж. Для рук и для лица, быстро эмульсируется, умывается теплой водой и всё чисто.

В следующем примере аргументирование сопровождается перечислением вредных компонентов, которые отсутствуют в рекламируемом продукте. Такой способ аргументирования очень эффективен и распространен во многих видах рекламы. 
非常温和, 没有香精, 没有酒精, 无刺激, 卸得非常干净。OчeHb мягкое, без эссенций, без спирта, не вызыьает раздражения, эффективно очищает.

Как отмечает Ли Яньди: «Блогеры-рекламщики будто говорят чистую правду, не хвалят чрезмерно качества и эффективность товара, а иногда указывают даже на его недостатки. Такие периодические отрицательные отзывы сделают продукт более убедительным» $[21,117]$. Например:

这个花酒的缺点是，不像别的花酒那样有喷射式的 “猛” 水流， 它的水流有点点小……不过完全不影响，这种小水流特别适合女 生, 对皮肤很好... Недостатком этого душа является то, ито, в оттичие от других душевых кабин, в нем нет струйного «бурного» потока воды, и его поток воды немного мал ... но это никак не влияет. Такой небольшой поток воды особенно подходит девушкам и хорошо для кожи ...

Коммуникативный ход «апелляция к авторитету»

Viya - известный блогер с огромной аудиторией, прославившаяся умением грамотно и эффективно продвигать товар. Её аудитория изначально ориентирована на то, чтобы покупать товары, которые она рекламирует, в связи с этим её мнение следует считать авторитетным.

В её видеороликах можно часто встретить такие простые фразы, как:

植树秀卸妆油。这个真的是我最喜欢的，也是我用的最久的一 款。Гидробильное масло SHU UEMURA. Это мое самое любимое, пользуюсь им очень давно.

我超级选这个水。 $Я$, не задумььваясь, сразу выбираю эту воду.

Мнение о продукте подкрепляется и личным опытом использования продукта. Во время прямого эфира Viya рассказывает о том, как выбирала товар для рекламы, о своем или членов её семьи опыте использования/употребления/примерки. Вплоть до того, что во время стрима она с напарницей сами стараются купить товар как можно быстрее.

В одном из эфиров она говорит:

我卖的东西, 是我自己一家老小都要吃的。我会把我自己不吃的 东西推荐给你们吗? Товары и продукты, которые я продаю, я сама и вся моя семья пробует. Разве я могу рекомендовать вам то, что сама не пробовала?

Приведем еще пример:

这款面膜我有用过, 而且我把它推荐给了我妈, 我妈现在每天都 在用... Этумаску для лииа я тоже пробовала, и рекомендовала её своей маме, она сейчас каждый день пользуется.

В прямом эфире Viya часто принимают участие представители или владельцы компании/бренда. Они рассказывают о своём продукте, делятся своим опытом и методами их использования. Viуа пригласила гонконгского актёра Гу Цзая рекламировать собственные продукты - средства для душа. Указывая на высокое качество продуктов, Viya отмечает:

因为我知道那个古仔他第一次研究产品的话, 他自己很严格的, 他对从原料开始都非常严格, 从原料到包装。Потому что я знаю, что, если Гу Цзай в первый раз выпускает продукт, то очень требователен к себе. Он очень требователен ко всему, начиная с ингредиентов и заканчивая упаковкой. 
3. Коммуникативная стратегия обращения к эмоциям

Тактика обращения к иенностям

Традиционно принято выделять материальные и духовные ценности. К материальным ценностям относят вещи, имеющие физическую форму и принадлежащие физическому лицу: деньги, дом, машина, предметы искусства, одежда и т. д. К нематериальным ценностям относят то, что невозможно измерить и дать цену: семья, любовь, свобода, вера, красота, здоровье и т. п. Эти ценности ориентируют человека в жизни, в том числе и в выборе товара.

Unnyclub的眼线笔很便宜几十块钱一支。Подводка для глаз от Unпусlаь очень дешёвая, несколько десятков юаней.

В приведенном примере аргументация, реализуемая на вербальном уровне, построена на апелляции к такой ценности, как деньги. Присутствие оценочного прилагательного 便宜 дешёвый воспринимается аудиторией, как положительное качество. Аргумент подкрепляется озвучиванием примерной цены продукта, что также должно установить позитивное отношение адресата к рекламируемому продукту.

Рассмотрим пример обращения к духовной ценности - счастью:

你不觉得看到这些口红就很开心吗? Тебе не кажется, что, увидев эти помады, ты становишься счастливей?

\section{4. Коммуникативная стратегия преимущества}

Тактика открытого сравнения

Очевидно, что в своих видеороликах Viya не озвучивает названия других брендов для сравнения рекламируемого объекта. В данном случае, под открытым сравнением мы имеем в виду рекламные сообщения, содержание которых представляет явное сравнение с другими брендами, однако эксплицитно не указывает с какими. Приведем пример:

其实我在前攒了这个沐浴露, 因为我当时拿了很多味道, 我第一 回被这个吸引, 因为这个味道的它的味道不是很浓丽, 很多品牌的 话你闻起来就有点香香的, 然后用起来有点油。这个完全不油。它 是一个果冻状的一个质地。 На самом деле, я хвалила этот гель для душа, потому что в тот раз я взяла много гелей с разным запахом. Меня это привлекло с первого раза, потому что его запах не очень резкий. У многих брендов гели для душа имеют сладкий запах, а когда наносишь, кожа становится немножко жирной. Этот гель совсем не жирный, имеет желейную текстуру.

Тактика скрытого сравнения

Эта тактика в неявном виде несёт сравнение с другими товарами, не упоминая ни названия, ни категории. В рекламе говорится, что характеристики товара лучше, эффективнее, но не указывается по сравнению с чем:

就是有时候你洗澡之后上身油淢感, 完全没有了。Иногда после душа чувствуешь, что кожа становится жирной, но в этом случае абсолютно нет.

В данном случае сравнение выражено имплицитно, то есть Viуа не называет в каком случае возникает такое ощущение, но явно подразумевает, что после использования средств других брендов. 


\section{Заключение}

Исследование показало, что Viya, являясь блогером, делающим рекламу в интернете, использует стратегии «лотереи» и стимулирования продаж, её мнение авторитетное, а общение ведётся в виде дружеской беседы. Она всегда относится к своим фанатам как к друзьям, когда общается с ними, всегда резюмирует все преимущества товара, к тому же всегда сама их пробует. Фанаты верят ей, поэтому её товары пользуются таким спросом.

Анализ автора выявил, что у Viуа стандартная стратегия и последовательность в представлении товара: преимущества/положительные стороны товара - скидки - обратный отсчет времени.

Описывая собственные преимущества товара, Viya предлагает очень низкую цену за товар при заказе во время прямого эфира, а также включает дополнительные подарки за большой заказ. Для стимулирования зрителей к покупке, Viya предоставляет различные скидки, купоны и подарки - это одна из главных причин эффективности продаж в прямом эфире. Это способствует тому, что у зрителей возникает чувство, будто они прогадают, если не купят.

B эфирах Viуa делает акцент на ценовых преимуществах товара, кроме того, рекламируя товар, Viуa рассказывает истории об опыте использования товара членами её семьи или её команды, тем самым отбрасывая все сомнения зрителей.

Ограничение количества товара на полках магазина создаётся для того, чтобы создать атмосферу напряжения и стимулировать зрителей к покупкам. Подчёркивая ограниченное время и ограниченное количество и в то же время обеспечивая льготные цены, VIуа постепенно побуждает потребителей к потреблению.

Стратегия завоевания потребителя и стратегия обращения к разуму применяются в рекламе Viya наиболее часто. На наш взгляд это связано с тем, что для стимулирования аудитории к покупке требуются убедительные аргументы, и с помощью этих двух стратегий можно в полной мере добиться, чтобы адресант задумался о покупке.

Со стилистической точки зрения можно отметить, что Viуa активно использует местоимения второго лица, которые создают атмосферу дружеского совета и мысленно приближают адресата к адресанту. В этом случае главная задача блогера заключается в том, чтобы, сохраняя эти воображаемые межличностные отношения, создать нужный эмоциональный настрой и сформировать положительное отношение к предлагаемому товару.

Кроме того, для рекламы Viуa характерны риторические вопросы, которые наводят на размышления о проблеме и о её решении, также применяются глаголы повелительного наклонения, побуждающие к совершению покупки.

Согласно анализу автора, речь Viуа в основном состоит из простых и коротких предложений. Предложения часто состоят из нескольких слов, иногда даже из одного слова. Простые и короткие предложения появляются чаще, поскольку блогеры-продавцы должны предоставить как можно больше информации за короткое время, они должны обращать внимание на принцип экономии языка. Короткие и лаконичные предложения более прямолинейны и понятны аудитории. 
Проведенное исследование позволяет утверждать, что рекламы Viya привлекательны для покупателей своей непосредственностью и простотой. Реклама товара подается в форме дружеской рекомендации - это вызывает доверие покупателей и формирует покупательское намерение аудитории.

\section{Литература}

1. Бернадская Ю.С. Приемы речевого воздействия в рекламе // Омский научный вестник. 2006. №10 (49). С. 112-116.

2. ван Дейк Т.А. Язык. Познание. Коммуникация. Благовещенск: БГК им. Бодуэна де Куртенэ, 2000. 312 с.

3. Гончарова Л.М. Коммуникативные возможности речевых тактик в рекламных текстах // Вестник Московского государственного областного университета. серия: русская филология. 2010. № 2. С. 21-25.

4. Горло Е.А. Речевое воздействие в поэтическом тексте // Известия ТРТУ. Гуманитарные науки в современном мире. 2006. №2 (57). С. 34-37.

5. Горячев А.А. Моделирование речевого воздействия в рекламной коммуникации: дисс. канд. филол. наук: 10.02.19. Санкт-Петербург, 2010. 289 с.

6. Иссерс О.С. Коммуникативные стратегии и тактики русской речи: монография: Изд. 5-е. - М.: Издательство ЛКИ, 2008. 288 с.

7. Клюев Е.В. Речевая коммуникация: учебное пособие для университетов и институтов. М.: Рипол Классик, 2002. 320 с.

8. Мальцева В.А. Стратегии речевого воздействия в профессиональной коммуникации: автореф. дис. на соиск. учен. степ. канд. филол. наук 10.02.19. - Челябинск, 2011.26 с.

9. Мирошниченко Г.А. Коммуникативная стратегия вербального убеждения в российской телевизионной рекламе // Вестник Российского университета дружбы народов. 2018. № 2. С. 215-223.

10. Статкевич Е.А. Речевые стратегии и тактики современной радиорекламы // Омский научный вестник. 2011. № 1(95). C. 212-215.

11. Страхова О.А. Коммуникативные тактики и ходы: к проблеме соотношения данных понятий // Альманах научных статей молодых ученых. 2018. С. 115-117.
12. Шелестюк Е.В. Речевое воздействие: Онтология и таксономия // Вопросы когнитивной лингвистики. Теоретические проблемы языкознания. 2007. №1 (10). C. 23-30.

13. Ou Ryokuyuu. Message strategies, Informativeness and Value Appealsin Chinese Television Advertising: An Empirical Study // Otaru University of Commerce . URL: http:// hdl.handle.net/10252/00005535 (дата обращения: 10.02.2021).

14. Karlsson, S. Advertising as Discourse // Linnéuniversitetet. Publications. URL: http:// lnu.diva-portal.org/smash/get/diva2:840756/ FULLTEXT01.pdf (дата обращения: 24.01.2021).

15. Wang, R. Native ShortVideo Advertising on Chinese Social Media // UF Libraries. URL: https://ufdc.ufl.edu/ UFE0052340 (дата обращения: 16.03.2021).

16. Zhang, L. Song, Jinjing. Analysis of Chinese millennial consumers' preference for online advertising channel in China // Jönköping University. URL: http://urn.kb.se/ resolve?urn=urn:nbn:se:hj:diva-49999 (дата обращения: 3.02.2021).

17. 李彦迪. 语域理论视角下电商主播 言语社区语言特征探析 - - 以淘宝主播微 娅和李佳琦为例 // 视听. 2021 (02). 第117118 页. = Ли Яньди. Анализ языковых особенностей видеоблогеров сферы электронной коммерции с точки зрения теории языковых регистров (на примере блогеров на площадке Taobao Viya и Ли Цзяци) // Radio\&TV Journal. 2021 (2). C. 117-118.

18. 张悦畅. 新媒体视域下电商网红店 主个人品牌化塑造 - - 以淘宝直播主播薇 娅为例 // 新媒体研究. 2019年. 第12期. 第 134-135页. Чжан Юэчан. Создание личного бренда владельцев интернет-магазинов знаменитостей в интернете с точки зрения новых медиа: на примере ведущего прямых эфиров на площадке Taobao Viya // New Media Research. 2019. № 12. C. 134-135. 
Aleksandr N. SBOEV,

Ph.D. (in Philological Sciences), Associate Professor, Department of Sinology, FEFU (Vladivostok, Russia).

E-mail: sboev.an@dvfu.ru

Antonina V. NOVGORODOVA,

Master in Oriental and African Studies, FEFU (Vladivostok, Russia).

E-mail: tonya.novgorodova@bk.ru

\section{Speech Manipulation in Chinese Web Advertising}

\section{UDC 811.581}

speech manipulation, speech strategy,

speech tactics, online advertising, blogger Viya
DOI https://doi.org/10.24866/2542-1611/2021-3/108-121

The results of speech manipulation research in different languages can be used to establish intercultural communication in various fields. This article is devoted to the study of speech manipulation, in particular to the analysis of the speech manipulation aspects on the material of the Chinese web advertising discourse (online advertising). Language data were collected from the Internet blogger Viya livestreaming with a total duration of about 6 hours. The research describes the standard communication strategy, tactics and also consistency in product presentation made by the popular Internet blogger Viya. We identified four main communication strategies used by Viya: speech strategy of conquering the consumer, speech strategy of appealing to someone's mind, speech strategy of appealing to someone's emotions and speech strategy of advantage. The analysis showed that the strategy of conquering the consumer and the strategy of appealing to someone's mind are the most often used strategies of Viya's advertising.

For citation: Sboev A. N., Novgorodova A. V. Speech manipulation in Chinese Web Advertising // Oriental Institute Journal. 2021. № 3. P. 108-121. DOI https://doi.org/10.24866/2542-1611/2021-3/108-121

\section{References}

1. Bernadskaya YU.S. Priemy rechevogo vozdejstviya $\mathrm{v}$ reklame // Omskij nauchnyj vestnik. 2006. №10 (49). S. 112-116.

2. van Dejk T.A. YAzyk. Poznanie. Kommunikatsiya. Blagoveshhensk: BGK im. Boduehna de Kurteneh, 2000.312 s.

3. Goncharova L.M. Kommunikativnye vozmozhnosti rechevykh taktik v reklamnykh tekstakh // Vestnik Moskovskogo gosudarstvennogo oblastnogo universiteta. seriya: russkaya filologiya. 2010. № 2. S. 2125.

4. Gorlo E.A. Rechevoe vozdejstvie v poehticheskom tekste // Izvestiya TRTU. Gumanitarnye nauki v sovremennom mire. 2006. №2 (57). S. 34-37.

5. Goryachev A.A. Modelirovanie rechevogo vozdejstviya $\mathrm{v}$ reklamnoj kommunikatsii: diss. kand. filol. nauk: 10.02.19. - Sankt-Peterburg, 2010. 289 s.

6. Issers O.S. Kommunikativnye strategii i taktiki russkoj rechi: monografiya: Izd. 5-e. M.: Izdatel'stvo LKI, 2008. 288 s.

7. Klyuev E.V. Rechevaya kommunikatsiya: uchebnoe posobie dlya universitetov i institutov. M.: Ripol Klassik, 2002. $320 \mathrm{~s}$.

8. Mal'tseva V.A. Strategii rechevogo vozdejstviya v professional'noj kommunikatsii: avtoref. dis. na soisk. uchen. step. kand. filol. nauk 10.02.19. - CHelyabinsk, 2011. 26 s.

9. Miroshnichenko Kommunikativnaya strategiya verbal'nogo ubezhdeniya v rossijskoj televizionnoj reklame 
// Vestnik Rossijskogo universiteta druzhby narodov. 2018. № 2. S. 215-223.

10. Statkevich E.A. Rechevye strategii i taktiki sovremennoj radioreklamy // Omskij nauchnyj vestnik. 2011. № 1(95). S. 212-215.

11. Strakhova O.A. Kommunikativnye taktiki i khody: $\mathrm{k}$ probleme sootnosheniya dannykh ponyatij // Al'manakh nauchnykh statej molodykh uchenykh. 2018. S. 115-117.

12. SHelestyuk E.V. Rechevoe vozdejstvie: Ontologiya i taksonomiya // Voprosy kognitivnoj lingvistiki. Teoreticheskie problemy yazykoznaniya. 2007. №1 (10). S. 23-30.

13. Ou Ryokuyuu. Message strategies, Informativeness and Value Appealsin Chinese Television Advertising: An Empirical Study // Otaru University of Commerce . URL: http://hdl.handle.net/10252/00005535 (data obrashheniya: 10.02.2021).

14. Karlsson, S. Advertising as Discourse // Linnéuniversitetet. Publications. URL: http:// lnu.diva-portal.org/smash/get/diva2:840756/ FULLTEXT01.pdf (data obrashheniya: 24.01.2021).

15. Wang, R. Native Short-Video Advertising on Chinese Social Media //
UF Libraries. URL: https://ufdc.ufl.edu/ UFE0052340 (data obrashheniya: 16.03.2021).

16. Zhang, L. Song, Jinjing. Analysis of Chinese millennial consumers' preference for online advertising channel in China // Jönköping University. URL: http://urn.kb.se/ resolve?urn=urn:nbn:se:hj:diva-49999 (data obrashheniya: 3.02.2021).

17. 李彦迪. 语域理论视角下电商主播言 语社区语言特征探析-- 以淘宝主播微娅和 李佳琦为例 // 视听. 2021 (02). 第117-118页. = Li YAn'di. Analiz yazykovykh osobennostej videoblogerov sfery ehlektronnoj kommertsii s tochki zreniya teorii yazykovykh registrov (na primere blogerov na ploshhadke Taobao Viya i Li TSzyatsi) // Radio\&TV Journal. 2021 (2). S. 117-118.

18. 张悦畅. 新媒体视域下电商网红 店主个人品牌化塑造-- 以淘宝直播主 播微娅为例 // 新媒体研究. 2019年. 第 12期. 第134-135页. CHzhan YUehchan. Sozdanie lichnogo brenda vladel'tsev internet-magazinov znamenitostej $\mathrm{v}$ internete s tochki zreniya novykh media: na primere vedushhego pryamykh ehfirov na ploshhadke Taobao Viya // New Media Research. 2019. № 12. S. 134-135. 